\title{
Research on Interruptible Load participating in electricity and reserve joint market
}

\author{
Haiyu Huang ${ }^{1}$, Chunming Wang ${ }^{1}$, Shaolian Xia ${ }^{1}$, Huaqiang Xiong ${ }^{1}$, Baofeng Jiang ${ }^{1}$, Dunnan Liu ${ }^{2}$ and GaoYuan ${ }^{2 *}$ \\ ${ }^{1}$ Central China Electric Power Dispatching and Control Sub-center of State Grid, Wuhan 430061, China
}

${ }^{2}$ State Key Laboratory of Alternate Electrical Power System With Renewable Energy Sources(North China Electric Power University), Changping District, Beijing 102206, China

\begin{abstract}
There is a shortage of power supply in multi provincial power grid during peak load period. The response speed of interruptible load is fast, and it has the same excellent regulation performance as the standby on the generation side, which can meet the needs of fast transfer. Aiming at the situation of interruptible load participating in the joint market under the bilateral mode, this paper designs the joint clearing process of electric energy and reserve market considering interruptible load, and establishes the joint clearing model considering interruptible load participating in electric energy and reserve market with the goal of maximizing social welfare. Simulation results verify the effectiveness of the proposed model.
\end{abstract}

\section{Introduction}

In recent years, there is a shortage of power supply during peak load period in many provinces. Fast interruptible load response speed is very fast, and has the same excellent regulation performance as the generation side standby, which can meet the needs of fast call. The interruptible load can cut off part of the load in the emergency period, which is equivalent to putting in the standby units. It can further tap the resource potential of the demand side, improve the power supply capacity in the peak period of the power grid, and help to alleviate the peak power supply tension of the power grid.

At present, scholars at home and abroad mainly study the participation of interruptible load in reserve market from the following aspects: first, from the perspective of the optimization model of interruptible load in reserve market. The objective function is to minimize the total cost of power grid companies to purchase reserve auxiliary services. Under the condition of system reliability and other reserve constraints, the mathematical model [1] is established. The optimal combination of interruptible load and generator unit is obtained by various algorithms (such as genetic algorithm [2], particle swarm optimization [3], Pareto optimization theory [4]). Secondly, the benefit calculation of interruptible load participating in reserve optimization is studied. Considering the outage loss of the user side and the outage compensation benefit, a joint optimization model of bilateral open reserve market is established to obtain the optimal reserve capacity combination [5]. Thirdly, the incentive design of interruptible load participating in reserve and contract management are studied. It is mainly through the design of electricity price to adjust the user income and power grid cost of IL [8]. Fourth, other aspects of optimization research, such as reserve capacity allocation from the perspective of risk [9], coordination and optimization of capacity from the perspective of power grid planning [10].

Aiming at the situation of interruptible load participating in joint market in bilateral mode, this paper designs a joint clearing process of power and reserve market considering interruptible load. With the goal of maximizing social welfare, a joint clearing model of power and reserve market considering interruptible load participating in joint market is established. Through the simulation of an example, the paper analyzes the uncertainty of interruptible load participating in energy and reserve joint market respectively .Compared with the simulation analysis of the same scenario, the changes of interruptible load revenue, system load peak valley difference, social welfare and other parameters in different scenarios are obtained, which verify the effectiveness of the proposed model.

\section{Clearing process design of electricity and reserve joint market considering interruptible load}

Referring to the clearing rules of Guangdong power market, considering the bilateral bidding mode of interruptible load participation, the clearing process of combined energy and reserve market considering interruptible load is designed. The specific clearing process is shown in the following steps.

Step 1: the power dispatching organization carries out day ahead market clearing and dispatching plan preparation in the day ahead stage. The electricity

\footnotetext{
* Corresponding author: gaoyuanhd@163.com
} 
market trading system is used to declare the day ahead electricity market trading of the generating units and the user side, the electricity demand and price curve is declared on the power side, and the generation quotation curve is declared by the generating units. Generators and interruptible load users participating in the reserve auxiliary service market shall declare the volume price curve of reserve auxiliary service.

Step 2: Taking the maximization of social benefits as the optimization objective, considering the generation side and user side volume price curves, system source load balance constraints, reserve capacity constraints, upper and lower limits of generator output, line power flow constraints, load characteristic constraints and other constraints of the electric energy market and reserve capacity market, the unit commitment (SCUC) with safety constraints is cleared, and the start and stop of the next 24 hours is calculated Plan.

Step 3: on the basis of known unit start-up and shutdown scheme, considering other related constraints besides unit start-up and shut-down constraints, the sced clearing with safety constraints is carried out, and the clearing results of joint optimization of electric energy and standby auxiliary services are calculated, so as to realize the economic distribution of load and generator output under the standby capacity market.

Step 4: according to the dual factor of sled model, calculate the next day $24 \mathrm{~h}$ energy and reserve market node price

Step 5: check the AC power flow safety of unit startup combination and unit output curve on the operation day. If the safety constraints are not met, add corresponding constraints in the calculation model and repeat steps 2, 3 and 4 until the constraints are met and the pre clearing results are obtained.

Under the mode of joint optimization of electric energy and reserve market, trading varieties mainly include electric energy and primary reserve. Primary reserve refers to the reserve that can respond to increase output or decrease load within 10 minutes.

The model contains unit start-up and stop variables, which are integer variables. Therefore, the joint clearing model is a mixed linear integer programming model (MILP), which can be solved by branch and bound method, cut plane method and other algorithms in theory. In this paper, CPLEX solver is used to solve the problem. Through the technical support system, SCUC and sced algorithms are used to optimize the calculation based on the declaration information of market participants and the grid operation boundary conditions on the operation day, and the day ahead market transaction results are obtained.

\section{Unit commitment model considering interruptible load in joint market}

\subsection{Interruptible load modeling}

The interruptible load modeling mainly considers the upper and lower limit constraints of the load and the bid winning reserve capacity and the interruption times constraints, which are respectively expressed as equations (1) to (3):

$$
\begin{gathered}
P_{1, i}(t)=1-I_{1, t}(t) P_{1, i, \max } \\
P_{1, i}(t)+R_{1, i}(t) \leq P_{1, i, \max } \\
\sum_{t=1}^{T} I_{1, i}(t) \leq N_{t}
\end{gathered}
$$

Where: $\mathrm{i}=1,2$, I, I are the number of interruptible loads and integrators of interruptible loads; $\mathrm{t}=1,2, \mathrm{t}, \mathrm{t}$ are the dispatching cycle; $P_{1, i}(t)$ is the power consumption of the ith interruptible load in the period $\mathrm{T} ; R_{1, i}(t)$ is the bid winning reserve capacity of the ith interruptible load in the period $\mathrm{T} ; P_{1, i, \max }$ is the maximum value of the $\mathrm{D}$ interruptible load; $I_{1, t}(t)$ is the state variable of the 1st interruptible load in the period $\mathrm{T}$; nis the maximum number of interruptions of the ith interruptible load in the dispatching cycle. $I_{1, t}(t)$ is $(0,1)$ variable: when $I_{1, t}(t)=1$, its means to interrupt the ith load; when $I_{1, t}(t)=0$, its means not to interrupt the load.

\subsection{Objective function}

The objective function of the mathematical model is to maximize the social welfare of the joint market and consider the security constraints of power grid operation.

$$
\begin{aligned}
& \operatorname{Max} F=\sum_{t=1}^{T}\left(\sum_{i=1}^{I} F_{1, i}(t)-\sum_{e=1}^{E} F_{e, e}(t)\right) \\
& -\sum_{t=1}^{T}\left(\sum_{e=1}^{E} L_{e, e}(t)+\sum_{i=1}^{I} L_{1, i}(t)+\sum_{c=1}^{C} S_{c}(t)\right)
\end{aligned}
$$

Where: $F_{1, i}(t)$ is the quoting function of power consumption benefit of the i-th interruptible load or interruptible load aggregator; $F_{e, e}(t)$ is the quoting function of generation cost of the e-th generating unit in period $\mathrm{t} ; L_{e, e}(t)$ is the quoting function of generating unit in reserve market; $L_{1, i}(t)$ is the quoting function of interruptible load in reserve market; ${ }_{c}(t)$ is the starting cost of the c-th coal-fired generating unit.

For generating cost $F_{\text {coal }}$ and start-up cost $S_{\text {coal }}$, the quotation functions are as follows:

$$
\begin{gathered}
F_{\text {coal }}(\mathrm{t})=\left(\mathrm{aP}^{2}(\mathrm{t})+\mathrm{bP}(\mathrm{t})+\mathrm{c}\right) \mathrm{I}(\mathrm{t}) \\
S_{\text {coal }}(\mathrm{t})=\mathrm{S}_{c}(t) I(t)(1-I(t-1))
\end{gathered}
$$

Among them, $\mathrm{P}(\mathrm{t})$ is coal power unit; The generating power in period $\mathrm{t}$; $\mathrm{a}, \mathrm{B}$ and $\mathrm{C}$ are the quoting coefficient of energy market; $I(t)$ is the start-up and stop state of coal-fired power unit in period $t$, with the value of 1 for start-up and 0 for shutdown.

The reserve dispatch cost quotation function is as follows:

$$
L(\mathrm{t})=\left(1 \mathrm{R}^{2}(\mathrm{t})+\mathrm{mR}(\mathrm{t})+\mathrm{n}\right) \mathrm{I}(\mathrm{t})
$$


Where: $1, \mathrm{~m}$ and $\mathrm{n}$ are the reserve market quotation coefficients respectively; $\mathrm{R}(\mathrm{t})$ is the bid winning reserve capacity provided by coal-fired power units in time period $t$.

The bidding functions of interruptible load in power market and reserve market are quadratic functions.

$$
\begin{array}{r}
F_{1, \mathrm{i}}(\mathrm{t})=\mathrm{a}_{1, i} \mathrm{P}_{1, i}{ }^{2}(\mathrm{t})+\mathrm{b}_{1, i} \mathrm{P}_{1, i}(\mathrm{t})+\mathrm{c}_{1, i} \\
L_{1, \mathrm{i}}(\mathrm{t})=\mathrm{l}_{1, i} R_{1, i}{ }^{2}(\mathrm{t})+\mathrm{m}_{1, i} R_{1, i}(\mathrm{t})+\mathrm{n}_{1, i}
\end{array}
$$

In the above formula, the coefficient is obtained from practical operation experience.

\subsection{Constraints}

1) System source load balance constraints:

$$
\begin{gathered}
\sum_{\mathrm{e}=1}^{E} P_{e, e}(e, t)+\sum_{d=1}^{D} T(d, t)=P(t) \\
P(t)=\sum_{i=1}^{I} P_{1, i}(t)+P_{2}(t)
\end{gathered}
$$

Where: $P_{e, e}(e, t)$ is the output of the e-th generating unit in period $\mathrm{t} P(t)$ is the total load in period $\mathrm{t} ; P_{2}(t)$ is the total load in period t. $T(d, t)$ is the power of the D inter provincial tie line in period $\mathrm{t}$.

2) Reserve capacity constraint:

$$
\sum_{\mathrm{e}=1}^{E} R_{e, e}(t)+\sum_{\mathrm{i}=1}^{I} R_{1, t}(t) \geq R(t)
$$

Where: $R(t)$ is the total reserve demand of period $\mathrm{t}$; $R_{e, e}(t)$ and $R_{1, t}(t)$ are the bid winning reserve capacity of generator unit and interruptible load in period $\mathrm{t}$ respectively.

3) Considering the upper and lower limits of unit output in reserve market

$$
\begin{gathered}
R_{e, e, \min } \leq P_{e, e}(t)+R_{e, e}(t) \leq P_{e, e, \max } \\
P_{e, e, \min } U_{e, e}(t) \leq P_{e, e}(t) \leq P_{e, e, \max } U_{e, e}(t) \\
R_{e, e, \min } I_{e, e}(t) \leq R_{e, e}(t) \leq P_{e, e, \max } I_{e, e}(t)
\end{gathered}
$$

In the formula, $U_{e, e}(t)$ and $I_{e, e}(t)$ are $(0,1)$ variables, $U_{e, e}(t)=1$ represents winning the bid in energy market, $U_{e, e}(t)=0$ represents losing the bid in energy market, $I_{e, e}(t)=1$ represents winning the bid in reserve capacity market, and $I_{e, e}(t)=0$ represents losing the bid in reserve capacity market. For a generator set, the necessary condition for $I_{e, e}(t)=1$ is $U_{e, e}(t)=1$.

4) Ramp rate constraint:

$-V_{e, e, D} U_{e, e}(t) \leq P_{e, e}(t)-P_{e, e}(t-1) \leq V_{e, e, U} U_{e, e}(t)$

Where, $V_{e, e, U}$ and $V_{e, e, D}$ are the upward and downward climbing rates of the e-th generating unit respectively.

\section{Example analysis}

In order to verify the effectiveness of the proposed model, a provincial power grid is used for calculation. The regional power grid consists of 9 coal-fired power units and 2 interruptible load integrators. The total power capacity of the region is $2474 \mathrm{MW}$. The total load forecast curve of a certain day is shown in Figure 1, in which the interruptible load accounts for $3.54 \%$. The detailed data of units and loads are shown in Tables 2 and 3 , in which the minimum startup and shutdown time of units is $6 \mathrm{~h}$.

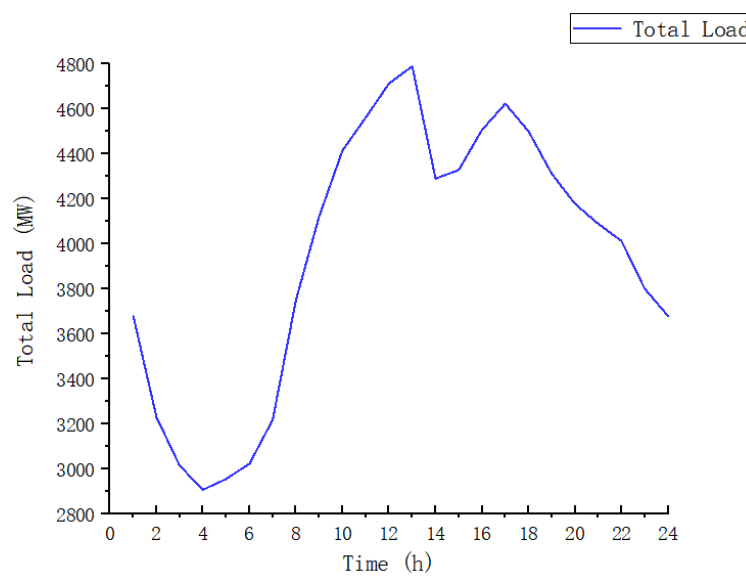

Fig. 1. Total load forecasting curve

Table 1. Unit information

\begin{tabular}{cccc}
\hline crew & $\begin{array}{c}\text { Upper limit } \\
\text { of } \\
\text { output/MW }\end{array}$ & $\begin{array}{c}\text { Lower limit } \\
\text { of } \\
\text { output/MW }\end{array}$ & $\begin{array}{c}\text { Climbing } \\
\text { rate/ } \\
\text { (MW/h) }\end{array}$ \\
\hline 1 & 350 & 170 & 120 \\
2 & 350 & 170 & 120 \\
3 & 350 & 170 & 120 \\
4 & 350 & 170 & 120 \\
5 & 330 & 160 & 100 \\
6 & 330 & 160 & 100 \\
7 & 138 & 80 & 50 \\
8 & 138 & 80 & 50 \\
9 & 138 & 80 & 50 \\
\hline
\end{tabular}

Table 2. Unit information

\begin{tabular}{cccccccc}
\hline crew & $\mathrm{a}$ & $\mathrm{b}$ & $\mathrm{c}$ & $\mathrm{l}$ & $\mathrm{m}$ & $\mathrm{n}$ & $\begin{array}{c}\text { start- } \\
\text { up } \\
\text { cost }\end{array}$ \\
\hline 1 & 0.02 & 400 & 10000 & 0.01 & 250 & 0 & 20 \\
2 & 0.03 & 600 & 9134 & 0.018 & 280 & 0 & 20 \\
3 & 0.032 & 578 & 6912 & 0.015 & 298 & 0 & 20 \\
4 & 0.1 & 580 & 11578 & 0.048 & 275 & 0 & 20 \\
5 & 0.42 & 600 & 12014 & 0.21 & 310 & 0 & 20 \\
6 & 0.5 & 556 & 10000 & 0.38 & 288 & 0 & 20 \\
7 & 0.39 & 576 & 9950 & 0.19 & 238 & 0 & 10 \\
8 & 0.7 & 642 & 12000 & 0.26 & 302 & 0 & 10 \\
9 & 0.8 & 666 & 9950 & 0.32 & 308 & 0 & 10 \\
\hline
\end{tabular}

Table 3. Load information

\begin{tabular}{ccc}
\hline Load type & Interruptible load & \\
\hline Capacity/MW & 60 & 80 \\
Number of & 10 & 13 \\
interruptions & &
\end{tabular}




\begin{tabular}{cccc} 
allowed & & & \\
Quoting & $\mathrm{A}$ & -0.0156 & -0.026 \\
coefficient of & $\mathrm{B}$ & 1000 & 850 \\
energy & $\mathrm{C}$ & 5 & 0 \\
market & 1 & 0.012 & 0.018 \\
$\begin{array}{c}\text { Quoting } \\
\text { coefficient of } \\
\text { reserve }\end{array}$ & $\mathrm{M}$ & 80 & 50 \\
market & $\mathrm{N}$ & 0 & 0 \\
\hline
\end{tabular}

The model is solved by CPLEX solver. By observing the start-up and stop of generating units, it can be seen that due to the peak cutting effect of interruptible load, some coal-fired power units with higher marginal cost withdraw from the market during the peak load period, and two units are opened less during the peak load period, which reduces the power production cost. In addition, due to interruptible load participating in the joint market, the bidding capacity of thermal power units in the reserve capacity market is squeezed, so that the bidding capacity of thermal power units in the reserve capacity market is 0 . The reason is that the marginal reserve cost of interruptible load is lower than that of thermal power unit. At the same time, after the interruptible load participates in the joint market, due to the effect of peak shaving, the bidding quantity of thermal power units during the peak period of power consumption is reduced. Before and after the interruptible load participates in the joint market of electric energy and reserve, the clearing price of electric energy in each period is shown in the figure.

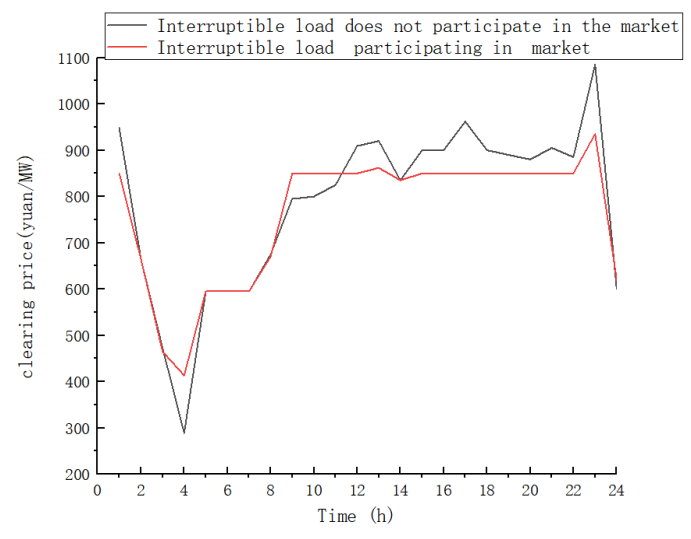

Fig. 2. Electricity clearing price change

It can be seen from Figure 2 that after interruptible loads participate in the joint clearing market, the average clearing price is reduced from 780.6 yuan / MW to 758.2 yuan / MW, which reduces the clearing price of electric energy and reduces the fluctuation degree of clearing price of electric energy, which is helpful for market players to improve their decision-making ability and risk control ability. Due to the low reserve cost of interruptible load, interruptible load can significantly reduce the clearing price of reserve capacity after participating in the joint market. After the interruptible load participates in the joint market, the production cost of electric energy is reduced, and the average clearing price of the system is reduced, so the power consumption cost of the load is reduced. In addition, the interruptible load participating in the joint clearing of energy market and auxiliary service market can reduce the peak valley difference of the system, relieve the peak shaving pressure of the power grid, improve the operation stability of the system, reduce the cost of power production and reserve scheduling of the system, and improve the overall social welfare. After the interruptible load participates in the joint market, its total revenue has been improved. The interruptible load reduces part of the power consumption, which leads to the reduction of its own power consumption income, but the loss of power consumption income is lower than the total income of the reserve market and the income after reducing the power consumption cost.

\section{Conclusion}

This paper establishes a joint clearing model of energy market and ancillary service market considering interruptible load, and studies the different scenarios of interruptible load before and after participating in the joint energy and reserve market under the mode of "generation side report quantity quotation and user side report quantity quotation". The simulation results show that the proposed model is effective. Under the condition of marketization, the response behavior of interruptible load is reasonably determined, and the load side is operated by means of market economy, so that it can not only meet the reliability of the system, but also realize the optimal economy on this basis, and meet the needs of users.

\section{Acknowledgments}

This work was supported in part by National Natural Science Foundation of China under Grant 72001078 and Power System State Key Laboratory under Grant SKLD20M12.

\section{References}

1. Xue Yusheng, Luo Yunhu, Li Bijun, Luo Jianyu, z.dong, g.ledwich. Review on Interruptible Load participating in system reserve .J. Power system automation, (2007)

2. Kong Xiangqing. Research on Interruptible Load participating in system reserve .D. Xihua University, (2012)

3. Huang Haiyu, Wang Chunming, Xia Shaolian, sun Xiaotian, Wang Yang. Design and practice of peak shaving auxiliary service market in Central China considering positive and negative rotating reserve .J. Power system automation, (2020)

4. Habibian M, Zakeri G, Downward A, et al. Cooptimization of demand response and interruptible load reserve offers for a price-making major consumer.J. Energy systems, (2020) 
5. Le A T . Interruptible Load Services in Deregulated Power Markets.J. Chalmers University of Technology, (2002)

6. Sun Xin, Tong Mingguang, Zhao Qingbo, Lin Haiying, Liu Min, Zeng Ming. Research on Interruptible Load Management Model in secondary backup auxiliary service market .J. Chinese Journal of electrical engineering, (2004)

7. Liang Wenju. Research on joint optimization of bilateral reserve capacity market .D. Hunan University, (2010)
8. Geng Yan. Reserve market research considering multiple demand response resources .D. North China Electric Power University (Beijing), (2016)

9. Ghasemi D H . Day-ahead scheduling of an active distribution network considering energy and reserve markets.J. International Transactions on Electrical Energy Systems, (2013)

10. Amirahmadi M , Boroomand N . Energy and spinning reserve markets scheduling considering interruptible load and demand-side reserve.C. IEEE International Conference on Power \& Energy. IEEE, (2017) 